\title{
Customer Flows, Countercyclical Markups, and the Output Effects of Technology Shocks*
}

This paper develops a general equilibrium model in which households face fixed costs associated with searching for a new supplier of consumption goods. These search costs provide firms with some monopoly power over their existing customers and generate the kind of customer flow dynamics first considered by Phelps and Winter. Customer flow dynamics, in turn, cause markups of price over marginal cost to vary countercyclically and amplify the effects of technology shocks on output.

\section{Introduction}

Real business cycle models, developed by Kydland and Prescott (1982) and Long and Plosser (1983) and extended by many others, successfully account for a wide range of empirical regularities associated with aggregate economic fluctuations. Strikingly, these models interpret much, if not all, of the cyclical variation in output as reflecting the impact of underlying shocks to the production function, or technology shocks. Yet, in practice, finding direct evidence of technology shocks, especially those that appear large enough to generate significant booms and recessions, proves difficult. This difficulty has been noted by severe critics of the real business cycle approach, including Summers (1986) and Mankiw (1989), as well as by more sympathetic reviewers, such as Lucas (1987) and McCallum (1989).

Motivated by this difficulty, this paper explores the effects of introducing a propagation mechanism not present in existing real business cycle models: the customer flow dynamics first considered by Phelps and Winter (1970). In particular, the paper shows that these customer flow dynamics can serve to amplify the output effects of technology shocks. Thus, with the addition of customer flow dynamics, business cycles can be generated by

*I would like to thank two anonymous referees, along with seminar participants at the Federal Reserve Bank of Chicago, George Washington University, North Carolina State, Ohio State, Rutgers, and Utah State for extremely helpful comments and suggestions. 
smaller technology shocks that may, therefore, be more difficult to identify in practice.

Bils (1989) presents a partial equilibrium model of customer flow dynamics, in which output fluctuations are driven not by technology shocks, but by exogenous shocks to demand. In Bils' model, a single monopolist supplies output to a set of customers who arrive in an infinite sequence of overlapping generations. Prior to actually buying the firm's output, each customer is unsure of how well the good will suit his tastes. Thus, a customer who does purchase the good in his first period of life and finds it to his liking develops an attachment to the firm. In this case, he becomes willing to pay a higher price for the good in his second period of life. Thus, in Bils' model as in Phelps and Winter's, the firm faces a trade-off: it can raise its price and thereby extract more surplus from its existing customers, or it can lower its price and thereby attract more new customers.

Bils demonstrates that these customer flow dynamics induce the monopolist to charge a markup of price over marginal cost that varies countercyclically. In some periods, high demand results from an especially large inflow of newly-born customers. It is precisely during these periods that the firm finds it most rewarding to lower its price in order to expand the size of its customer base. Hence, periods of high demand coincide with periods of low prices and, since marginal costs are constant, low markups as well. These countercyclical markups imply that market-clearing prices work in Bils' model to amplify, rather than stabilize, movements in output relative to demand.

This paper modifies and extends Bils' analysis so that it takes place in a general equilibrium setting where all agents are infinitely-lived and where aggregate fluctuations are driven by technology shocks. The model developed here begins by pairing each household with one of a large number of firms as its initial supplier of consumption goods and then confronts the representative household with a fixed cost of searching for a new supplier. This search cost gives the representative firm some monopoly power, enabling it to raise its price above those of all other firms while still retaining some of its customers.

In this model, when output increases after a positive technology shock, so does the size of each household's purchase of consumption goods. This increase in the size of each purchase strengthens the representative household's incentive to search for a new supplier; the cost of search, meanwhile, remains fixed. Consequently, search activity increases during periods of high output, eroding the representative firm's monopoly power and decreasing the equilibrium markup of price over marginal cost. These countercyclical markups work to amplify the effects of technology shocks on output. Nu- 
merical analysis reveals, for instance, that the output effects of a permanent technology shock can be magnified by as much as $80 \%$ when customer flows and countercyclical markups are accounted for. Moreover, this amplification becomes even stronger in the case of less persistent shocks: the output effects of a purely transitory shock in the model with customer flows can be more than nine times larger than they would be in a perfectly competitive setting.

While the customer flow mechanism is used here to generate markup fluctuations over the business cycle, evidence suggests that it may operate at higher frequencies as well. Warner and Barksy (1995), for instance, find that most retail price markdowns occur during the holiday shopping period between Thanksgiving and Christmas and on weekends, when demand is highest. They argue that this pricing behavior can be explained if customers search more intensively when making larger purchases, as they do in the model presented here. The model's implications are, in addition, consistent with evidence presented by Bils (1987), Rotemberg and Woodford (1991), and Morrison (1993), all of whom find that markups of price over marginal cost vary countercyclically in the U.S. data.

\section{Customer Flow Dynamics}

\section{The Economic Environment}

The economy consists of a continuum of firms indexed by $i \in[0,1]$ and a continuum of households indexed by $j \in[0,1] \times[0,1]$. Thus, there are both a large number of firms and a large number of households per firm. Time is discrete and indexed by $t=0,1,2, \ldots$

At the beginning of period $t$, each firm $i$ is matched with a continuum of households of measure $x_{i t}$. These households are the firm's initial customers, and the firm is the households' initial supplier, during period $t$. Each household observes its initial supplier's price, but knows only the distribution of the other firms' prices.

It is assumed that firms begin period $t=0$ with equal numbers of customers, so that $x_{i 0}=1$ for all $i \in[0,1]$. An altemative would be to assume that customers are initially unattached to the firms. Results derived by Klemperer (1987), using a two-period model with consumer switching costs, suggest that this alternative assumption would lead to an initial period during which firms compete aggressively to attract the unattached customers. Thus, by matching each customer with a firm at the beginning of time, the analysis here abstracts from this initial period of unusually aggressive competition. 
Household $j$ has preferences described by the expected utility function

$$
E\left\{\sum_{t=0}^{\infty} \beta^{t}\left[2\left(\theta_{j t}^{1-s_{j t}} c_{j t}\right)^{1 / 2}-n_{j t}-\kappa s_{j t}\right]\right\}
$$

where $\beta \in(0,1)$ is a constant discount factor, $c_{j t}$ is the household's consumption, and $n_{j t}$ is its labor supply during period $t$. The idiosyncratic shock $\theta_{j t}$ takes on values in the interval $\left[\theta_{l}, \theta_{h}\right]$ and is independently and identically distributed over time for each household with distribution function $F$ and density function $f$. It is assumed that the distribution of shocks across households is such that during each period $t$, the fraction $F(\theta)$ of each firm's initial customers have $\theta_{j i} \leq 0$. It is also assumed that $f^{\prime}(\theta) \geq 0$ for all $\theta \leq 1$; the significance of this assumption is discussed below. The $\theta_{j t}$ shocks are realized before agents have made any of their decisions for period $t$.

Household $j$ s s choice variable $s_{j t}$ equals zero if the household purchases output from its initial supplier during period $t ; s_{j t}$ equals one if the household purchases output from any other firm. Thus, as in Ball and Romer (1990), $\theta_{j t}$ measures household $j$ 's preference for remaining with its initial supplier during period $t$; in terms of utility, it values one unit of output from its initial supplier the same as $\theta_{j t}$ units of output from any other firm. The $\theta_{j t}$ shocks, therefore, provide households with a motive for search; those with lower values of $\theta_{j t}$ have a stronger incentive to look for a new supplier during pe$\operatorname{riod} t$.

If household $j$ decides to leave its initial supplier during period $t$, it must pay the fixed search cost $\kappa>0$; since the household's utility function is linear in labor supply, $\kappa$ may be interpreted as a time cost. Through the process of search, the household is matched randomly with one of the other firms, which becomes its second supplier during period $t$. During period $t$, the household's decision to search is final and can be made only once; if household $j$ does leave its initial supplier, it must purchase output from its second supplier. The household's second supplier during period $t$ then becomes its initial supplier during period $t+1$.

Consistent with Phelps and Winter's (1970) original specification, it is assumed that the probability that a searching household gets any firm $i$ as a second supplier is proportional to $x_{i t}$, the size of the firm's initial customer base. Thus, larger firms are more likely to attract new customers. The informational restrictions that give rise to this probability structure are not explicitly modeled here. Phelps and Winter suggest, however, that such a matching process might arise if information about market opportunities is transmitted through random meetings between households. Since any 
searching household is more likely to encounter an existing customer of a firm with a larger market share, larger firms will, on average, attract more searching households.

Labor, meanwhile, is perfectly mobile across firms and is paid the competitive wage $w_{t}$ during period $t$. Firm $i$ hires $l_{i t}$ units of labor to produce $y_{i t}$ units of output according to

$$
y_{i t}=z_{t} l_{i t}
$$

where $z_{t}$ is the aggregate technology shock during period $t$. For simplicity, it is assumed that all agents know the entire sequence $\left\{z_{t}\right\}_{t=0}^{\infty}$ at the beginning of period $t=0$. During period $t$, therefore, firm $i$ earns profits

$$
\pi_{i t}=p_{i t} y_{i t}-w_{t} l_{i t}=\left(p_{i t}-w_{t} / z_{t}\right) y_{i t},
$$

where $p_{i t}$ is its output price. It distributes these profits in equal shares to all households.

Although other types of equilibria cannot be ruled out, the analysis here focuses on symmetric equilibria, in which all firms charge the same price during each period $t$, so that $p_{i t}=p_{t}$ for all $i \in[0,1]$. Let $p^{0}$ $=\left\{p_{t}\right\}_{t=0}^{\infty}$ denote the entire sequence of these common prices; let $p^{t}$ $=\left\{p_{t+k}\right\}_{k=0}^{\infty}$ denote the subsequence of prices from period $t$ forward. In any symmetric equilibrium, no firm can have an incentive to charge a different sequence of prices $q^{0}=\left\{q_{t}\right\}_{t=0}^{\infty}$, with $q_{t} \neq p_{t}$ for some $t \geq 0$. Hence, the analysis begins by considering the optimizing behavior of a representative household whose initial supplier plans to charge an arbitrary sequence of prices $q^{t}=\left\{q_{t+k}\right\}_{k=0}^{\infty}$ from period $t$ forward while all other firms charge prices $p^{t}$. This behavior-and, in particular, its effect on the firm's profitsis then used to characterize the conditions under which the firm has no incentive to deviate from a candidate equilibrium price sequence $p^{0}$.

\section{Household Optimization}

Consider a representative household whose initial supplier during period $t$ plans to charge prices given by the sequence $q^{t}$. If all other firms charge prices $p^{t}$, the household's knowledge of the distribution of the other firms' prices allows it to know with certainty that if it leaves its initial supplier, it will be matched with a second supplier charging $p^{t}$.

Let $u\left(\theta_{j t} ; q^{t}\right)$ denote the maximized value of the household's expected utility from period $t$ forward, given that it experiences shock $\theta_{j t}$ during period $t$ and its initial supplier plans to charge prices $q^{t}$ from period $t$ forward. Then $u\left(\theta_{j t} ; q^{t}\right)$ must satisfy the Bellman equation 
Peter N. Ireland

$$
\begin{aligned}
u\left(\theta_{j t} ; q^{t}\right)= & \max 2\left[(1-s)\left(\theta_{j t} c^{0}\right)^{1 / 2}+s\left(c^{1}\right)^{1 / 2}\right]-(1-s) n^{0}-s\left(n^{1}+\kappa\right) \\
& +\beta E\left[(1-s) u\left(\theta_{j t+1} ; q^{t+1}\right)+s u\left(\theta_{j t+1} ; p^{t+1}\right)\right],
\end{aligned}
$$

where the expectation is taken over realizations of $\theta_{j t+1}$. The maximization in (1) is by choice of positive constants $c^{0}, n^{0}, c^{1}$, and $n^{1}$ and $s \in\{0,1\}$ that satisfy the budget constraints

$$
\pi_{t}+w_{t} n^{0} \geq q_{t} c^{0}
$$

and

$$
\pi_{t}+w_{t} n^{1} \geq p_{t} c^{1}
$$

where $\pi_{t}$ denotes the household's share of firm profits in period $t, c^{0}$ and $n^{0}$ denote the household's consumption and labor supply if it decides to remain with its initial supplier during period $t$, and $c^{1}$ and $n^{1}$ denote its consumption and labor supply if it decides to search for a second supplier.

The household's optimal choices for $c^{0}, n^{0}, c^{1}$, and $n^{1}$ are given by

$$
c^{0}=\theta_{j t}\left(w_{t} / q_{t}\right)^{2}
$$

and

$$
c^{1}=\left(w_{t} / p_{t}\right)^{2},
$$

along with (2) and (3) with equality. Substituting these optimal choices back into (1) reveals that the household will remain with its initial supplier, choosing $s=0$, if and only if

$$
\theta_{j t} \geq\left(q_{t} / p_{t}\right)\left(1-\left\{\kappa+\beta E\left[u\left(\theta_{j t+1} ; q^{t+1}\right)-u\left(\theta_{j t+1} ; p^{t+1}\right)\right]\right\} /\left(w_{t} / p_{t}\right)\right) .
$$

\section{Firm Optimization}

Next, consider a representative firm that begins period $t$ with a set of initial customers of measure $x_{i t}$. If this firm charges prices $q^{t}$ from period $t$ forward while all other firms charge prices $p^{t}$, it retains all of its initial customers with $\theta_{j t}$ satisfying (6).

Equation (6) reveals that here, as in Bils (1989), a time-consistency problem arises. Specifically, the representative firm can prevent some of its initial customers from leaving during period $t$ by promising to charge a low price $q_{t+1}$ during period $t+1$, since the representative household's gain in expected future utility from remaining with the firm instead of searching, 
given by $\beta E\left[u\left(\theta_{j t+1} ; q^{t+1}\right)-u\left(\theta_{j t+1} ; p^{t+1}\right)\right]$ in $(6)$, is decreasing as a function of $q_{t+1}$. Once period $t+1$ arrives, however, the firm has an incentive to charge a higher price $q_{t+1}$ than originally promised.

This problem is resolved here, as in Bils (1989), by focusing on timeconsistent equilibria in which firms choose their prices sequentially, periodby-period. Thus, when choosing its optimal price $q_{t}$ during period $t$, the representative firm takes $q^{t+1}$ as given, to be determined by decisions made in the future. Hence, the firm also takes

$$
\theta_{t}^{0}=1-\left\{\mathbf{k}+\beta E\left[u\left(\theta_{j t+1} ; q^{t+1}\right)-u\left(\theta_{j t+1} ; p^{t+1}\right)\right]\right\} /\left(w_{t} / p_{t}\right)
$$

as given when choosing $q_{t}$. In symmetric equilibria, where $q^{t+1}=p^{t+1}$, (7) simplifies to

$$
\theta_{t}^{0}=1-\kappa /\left(w_{t} / p_{t}\right)
$$

Accordingly, if the representative firm decides to charge price $p_{t}$ during period $t$, it retains all of its initial customers with $\theta_{j t} \geq\left\langle q_{t} / p_{t}\right) \theta_{t}^{0}$. This set of customers has measure $x_{i t}\left\{1-F\left[\left(q_{t} / p_{t}\right) \theta_{t}^{0}\right]\right\}$, and (4) implies that each of these customers purchases $\theta_{j t}\left(w_{t} / q_{t}\right)^{2}$ units of output. Since all other firms charge price $p_{t}$, and since searching households are matched with the representative firm in proportion to $x_{i t}$, the firm also gains a set of new customers of measure $x_{i t} F\left(\theta_{t}^{0}\right)$, and (5) implies that each of these customers purchases $\left(w_{t} / q_{t}\right)^{2}$ units of output. Hence, the firm faces total demand

$$
x_{t t}\left(w_{t} / q_{t}\right)^{2} h\left(q_{t} / p_{t} ; \theta_{t}^{0}\right)
$$

where

$$
h\left(q_{t} / p_{t} ; \theta_{t}^{0}\right)=F\left(\theta_{t}^{0}\right)+\int_{\left(q_{t} p_{t}\right) \theta_{t}^{0}}^{\theta_{h}} \theta f(\theta) d \theta
$$

and earns profits of

$$
\pi_{i t}=\left(q_{t}-w_{t} / z_{t}\right) x_{i t}\left(w_{t} / q_{t}\right)^{2} h\left(q_{t} / p_{t} ; \theta_{t}^{0}\right)
$$

during period $t$.

The firm then begins period $t+1$ with a new set of initial customers of measure 
Peter N. Ireland

$$
x_{i t+1}=x_{i t} \delta\left(q_{t} p_{t} ; \theta_{t}^{0}\right),
$$

where

$$
\delta\left(q_{t} / p_{t} ; \theta_{t}^{0}\right)=1-F\left[\left(q_{t} / p_{t}\right) \theta_{t}^{0}\right]+F\left(\theta_{t}^{0}\right) .
$$

Note, in particular, that $\delta\left(q_{t} / p_{t} ; \theta_{t}^{0}\right) \geq 1$ when $q_{t} \leq p_{t}$ and $\delta\left(q_{t} / p_{t} ; \theta_{t}^{0}\right) \leq 1$ when $q_{t} \geq p_{t}$. Thus, as in Phelps and Winter (1970), the representative firm gains customers if it charges a price below those of all other firms and loses customers if it charges a price above those of all other firms. As in Gottfries (1986), each household's $\theta_{j t}$ must be random over time to make $\delta$ a fixed function of $q_{t} / p_{t}$ and $\theta_{t}^{0}$.

Firms face no uncertainty in this environment. The representative firm seeks to maximize its total market value, equal to the sum of its current and future profits, discounted over time by the representative household's marginal utility of income, which in this case is simply

$$
\sum_{k=0}^{\infty} \beta^{k}\left(\pi_{i t+k} / w_{t+k}\right),
$$

during period $t$.

Given $\theta_{t}^{0}$ and $z_{t}$, let $v\left(x_{i t} ; \theta_{t}^{0}, z_{t}\right)$ denote the maximized value of $(9)$ when the representative firm begins period $t$ with a set of initial customers of measure $x_{i t}$. Then $v\left(x_{i t} ; \theta_{t}^{0}, z_{t}\right)$ must satisfy the Bellman equation

$$
\begin{aligned}
v\left(x_{i t} ; \theta_{t}^{0}, z_{t}\right)= & \max _{q>0}\left(q / w_{t}-1 / z_{t}\right) x_{i t}\left(w_{t} / q\right)^{2} h\left(q / p_{t} ; \theta_{t}^{0}\right) \\
& +\beta v\left[x_{t t} \delta\left(q / p_{t} ; \theta_{t}^{0}\right) ; \theta_{t+1}^{0}, z_{t+1}\right]
\end{aligned}
$$

Equation (10) indicates that here, as in Phelps and Winter (1970) and Bils (1989), the firm faces a trade-off. By raising its current price $q$, the firm extracts more surplus from some of its customers. At the same time, however, this price increase drives away other customers; this effect works not only to reduce current profits through the term $h\left(q / p_{t} ; \theta_{t}^{0}\right)$, but also to reduce future profits through the term $\delta\left(q / p_{t} ; \theta_{t}^{0}\right)$ in $(10)$.

The first-order and envelope conditions for (10) determine the outcome of this trade-off; they are 
Customer Flows, Countercyclical Markups

$$
\begin{aligned}
0= & x_{i t}\left(1 / w_{t}\right)\left(w_{t} / q\right)^{2} h\left(q / p_{t} ; \theta_{t}^{0}\right)-2\left(q / w_{t}-1 / z_{t}\right) x_{i t}\left(w_{t} / q\right)^{2}(1 / q) h\left(q / p_{t} ; \theta_{t}^{0}\right) \\
& +\left(q / w_{t}-1 / z_{t}\right) x_{i t}\left(w_{t} / q\right)^{2}\left(1 / p_{t}\right) h^{\prime}\left(q / p_{t} ; \theta_{t}^{0}\right) \\
& +\beta x_{i t}\left(1 / p_{t}\right) \delta^{\prime}\left(q / p_{t} ; \theta_{t}^{0}\right) v^{\prime}\left(x_{i t+1} ; \theta_{t+1}^{0}, z_{t+1}\right)
\end{aligned}
$$

and

$$
\begin{aligned}
v^{\prime}\left(x_{i t} ; \theta_{t}^{0}, z_{t}\right)= & \left(q / w_{t}-1 / z_{t}\right)\left(w_{t} / q\right)^{2} h\left(q / p_{t} ; \theta_{t}^{0}\right) \\
& +\beta \delta\left(q / p_{t} ; \theta_{t}^{0}\right) v^{\prime}\left(x_{i t+1} ; \theta_{t+1}^{0}, z_{t+1}\right)
\end{aligned}
$$

where

$$
h^{\prime}\left(q / p_{t} ; \theta_{t}^{0}\right)=-\left(q / p_{t}\right)\left(\theta_{t}^{0}\right)^{2} f\left[\left(q / p_{t}\right) \theta_{t}^{0}\right]
$$

and

$$
\delta^{\prime}\left(q / p_{t} ; \theta_{t}^{0}\right)=-\theta_{t}^{0} f\left[\left(q / p_{t}\right) \theta_{t}^{0}\right]
$$

\section{Equilibrium}

In a symmetric equilibrium, $q=p_{t}$ and $x_{i t}=x_{i t+1}=1$ for all $t \geq 0$. Imposing these conditions, and noting that they imply $\delta\left(1 ; \theta_{t}^{0}\right)=1,(11)$ and (12) become

$$
\begin{aligned}
0= & \left(w_{t} / p_{t}\right) h\left(1 ; \theta_{t}^{0}\right)-2\left(w_{t} / p_{t}\right)\left[1-\left(w_{t} / p_{t}\right)\left(1 / z_{t}\right)\right] h\left(1 ; \theta_{t}^{0}\right) \\
& +\left(w_{t} / p_{t}\right)\left[1-\left(w_{t} / p_{t}\right)\left(1 / z_{t}\right)\right] h^{\prime}\left(1 ; \theta_{t}^{0}\right)+\beta \delta^{\prime}\left(1 ; \theta_{t}^{0}\right) v^{\prime}\left(1 ; \theta_{t+1}^{0}, z_{t+1}\right)
\end{aligned}
$$

and

$$
v^{\prime}\left(1 ; \theta_{t}^{0}, z_{t}\right)=\left(w_{t} / p_{t}\right)\left[1-\left(w_{t} / p_{t}\right)\left(1 / z_{t}\right)\right] h\left(1 ; \theta_{t}^{0}\right)+\beta v^{\prime}\left(1 ; \theta_{t+1}^{0}, z_{t+1}\right)
$$

Note that these conditions, along with (8), only pin down the relative price $\omega_{t}=w_{t} / p_{t}$; determining absolute prices requires a choice of numeraire. Hence, they can be written as

$$
\begin{aligned}
0= & \omega_{t} h\left(1 ; \theta_{t}^{0}\right)-2 \omega_{t}\left(1-\omega_{t} / z_{t}\right) h\left(1 ; \theta_{t}^{0}\right)+\omega_{t}\left(1-\omega_{t} / z_{t}\right) h^{\prime}\left(1 ; \theta_{t}^{0}\right) \\
& +\beta \delta^{\prime}\left(1 ; \theta_{t}^{0}\right) v^{\prime}\left(1 ; \theta_{t+1}^{0}, z_{t+1}\right)
\end{aligned}
$$

and 
Peter N. Ireland

$$
v^{\prime}\left(1 ; \theta_{t}^{0}, z_{t}\right)=\omega_{t}\left(1-\omega_{t} / z_{t}\right) h\left(1 ; \theta_{t}^{0}\right)+\beta v^{\prime}\left(1 ; \theta_{t+1}^{0}, z_{t+1}\right),
$$

where

$$
\theta_{t}^{0}=1-\kappa / \omega_{t}
$$

Given the sequence $\left\{z_{t}\right\}_{t=0}^{\infty},(13)-(15)$ determine values for $\omega_{t}, v^{\prime}\left(1 ; \theta_{t}^{0}, z_{t}\right)$, and $\theta_{t}^{0}$ for all $t \geq 0$. Given these solutions, all other variables are easily constructed, so that (13)-(15) completely summarize an equilibrium for this economy.

\section{Countercyclical Markups}

\section{Steady-State Markups}

When $z_{t}=z$ for all $t \geq 0$, (13)-(15) describe steady-state equilibria in which $\omega_{t}=\omega$ and $\theta_{t}^{0}=\theta^{0}$ for all $t \geq 0$. In particular, (15) implies that $\theta^{0}=1-\kappa / \omega$, while (13) and (14) imply that $\omega$ must satisfy

$$
\begin{aligned}
0= & h\left(1 ; \theta^{0}\right)-2(1-\omega / z) h\left(1 ; \theta^{0}\right)+(1-\omega / z) h^{\prime}\left(1 ; \theta^{0}\right) \\
& +[\beta /(1-\beta)](1-\omega / z) h\left(1 ; \theta^{0}\right) \delta^{\prime}\left(1 ; \delta^{0}\right) .
\end{aligned}
$$

Equation (16) is highly nonlinear; in general, analytic solutions fail to exist. However, two special cases for which explicit solutions can be found serve to highlight some of the model's key implications.

First, as $\kappa$ becomes arbitrarily large, $h^{\prime}\left(1 ; \theta^{0}\right)$ and $\delta^{\prime}\left(1 ; \theta^{0}\right)$ approach zero, so that (16) implies that the steady-state markup of price over marginal cost, $z / \omega$, approaches two. In this case, infinite search costs give firms full monopoly power. Equation (4) shows that each household's elasticity of demand is $\varepsilon=-2$. Hence, the usual formula for the monopolistic markup applies: $\varepsilon /(\varepsilon+1)=2$.

Second, as $\boldsymbol{\kappa}$ becomes arbitrarily small and as both $\theta_{l}$ and $\theta_{h}$ approach unity, $h^{\prime}\left(1 ; \theta^{0}\right)$ and $\delta^{\prime}\left(1 ; \theta^{0}\right)$ approach negative infinity, so that (16) implies that $z / \omega$ converges to one. In this case, households regard all goods as perfect substitutes and can move freely between firms. Hence, the competitive outcome obtains: price equals marginal cost.

More generally, the steady-state markup lies somewhere between the monopolistic and competitive solutions; as in Phelps and Winter (1970), the representative firm enjoys only limited monopoly power over its customers. And while analytic solutions to (16) are no longer available, numerical so- 
TABLE 1. The Response of Markups and Output to Technology Shocks.

\begin{tabular}{|c|c|c|c|c|c|}
\hline \multirow[b]{2}{*}{$\kappa$} & \multirow{2}{*}{$\begin{array}{c}\text { Initial } \\
\text { Steady-State } \\
\text { Markup }\end{array}$} & \multicolumn{2}{|c|}{$\begin{array}{c}\text { Following a } \\
\text { Permanent Shock }\end{array}$} & \multicolumn{2}{|c|}{$\begin{array}{c}\text { Following a } \\
\text { Transitory Shock }\end{array}$} \\
\hline & & Markup & $\begin{array}{l}\text { Increase in } \\
\text { Output }\end{array}$ & Markup & $\begin{array}{c}\text { Increase in } \\
\text { Output }\end{array}$ \\
\hline 0.004 & $4.25 \%$ & $4.22 \%$ & $1.05 \%$ & $4.19 \%$ & $1.10 \%$ \\
\hline 0.005 & 5.84 & 5.79 & 1.09 & 5.66 & 1.33 \\
\hline 0.006 & 8.26 & 8.17 & 1.17 & 7.85 & 1.76 \\
\hline 0.007 & 12.26 & 12.08 & 1.34 & 11.25 & 2.85 \\
\hline 0.008 & 20.22 & 19.74 & 1.80 & 15.65 & 9.13 \\
\hline
\end{tabular}

lutions can be found by choosing a specific form for the distribution function $F$ and assigning values to the model's parameters.

Thus, let $\theta$ have a normal distribution with mean $\bar{\theta}$ and standard deviation $\sigma$, truncated at $\theta_{l}>0$ and $\theta_{h}<\infty$. With $\bar{\theta}=1.025$, households prefer to remain with their initial suppliers, on average. With $\theta_{l}=0.001$, the distribution is truncated close to zero; with $\theta_{h}=2.049$, the distribution is symmetric about $\bar{\theta}$. In this case, with $\sigma=0.01, \beta=0.975$, and $z=1$, the second column of Table 1 reports the steady-state markup, $z / \omega$, implied by various values of $\kappa$. Larger values of $\kappa$ imply higher search costs and hence higher steady-state markups. Thus, the markups range from $4.25 \%(z / \omega$ $=1.0425)$ when $\mathrm{\kappa}=0.004$ to more than $20 \%(z / \omega=1.2022)$ when $\mathbf{\kappa}$ $=0.008$.

The Response of Markups and Output to Technology Shocks

The third and fourth columns of Table 1 display the effects of a permanent technology shock on markups and aggregate output, which by (4)(7) is given by $y_{t}=\omega_{t}^{2} h\left(1 ; \theta_{t}^{0}\right)$ in a symmetric equilibrium. For each value of $\kappa$, the economy begins in the steady state where agents expect $z_{t}$ to remain constant at $z=1$ forever. Then, at the start of period $t=0, z_{t}$ jumps permanently to $z=(1.01)^{1 / 2}$. The economy moves immediately to a new steady state, described by the solution to (16) under the new value of $z$. Markups are lower, and aggregate output is higher, following the shock. Thus, markups are countercyclical.

Under perfect competition, the increase from $z=1$ to $z=(1.01)^{1 / 2}$ generates an increase in output of exactly $1 \%$. Thus, the fourth column of Table 1 reveals that the countercyclical markups work to amplify the effects of the technology shock on output. With $\kappa=0.004$, for instance, the fall in the markup from $4.25 \%$ to $4.22 \%$ contributes to a total increase in output 
of $1.05 \%$. The amplification grows larger as $\kappa$ rises; with $\kappa=0.008$, the markup declines from $20.22 \%$ to $19.74 \%$, contributing to a $1.80 \%$ increase in output.

The fifth and sixth columns of Table 1 illustrate the effects of a purely transitory technology shock. As before, the economy begins in the steady state where agents expect $z_{t}$ to remain constant at $z=1$ forever. At the beginning of period $t=0$, however, agents learn that the sequence $\left\{z_{t}\right\}_{t=0}^{\infty}$ will have $z_{0}=(1.01)^{1 / 2}$ and $z_{t}=1$ for all $t \geq 1$ instead. Equations (13) $-(15)$ imply that in response to this transitory shock, the markup falls and output rises during period $t=0$; both variables return to their initial steady-state values in period $t=1$. Thus, once again, markups are countercyclical, serving to amplify the effects of the technology shock. With $\kappa=0.004$, the markup falls from $4.25 \%$ to $4.19 \%$, and output rises by $1.10 \%$, after the transitory shock. With $\kappa=0.008$, the markup falls from $20.22 \%$ to $15.65 \%$, while output rises by $9.13 \%$. In this last case, therefore, the output effects of the technology shock are more than nine times larger than they would be in a perfectly competitive economy.

\section{The Sources of Countercyclical Markups}

To understand how customer flow dynamics give rise to countercyclical markups in this environment, note first that (6), (7), and (15) imply that in a symmetric equilibrium, household $j$ remains with its initial supplier during period $t$ if and only if

$$
\kappa \geq \omega_{t}\left(1-\theta_{j t}\right)
$$

For a household with $\theta_{j t}<1$, the right-hand side of (17) represents the utility cost of remaining with its initial supplier or, equivalently, the benefit of searching. This benefit increases with $\omega_{t}$ since, as shown by (4) and (5), the size of the household's purchase also increases with $\omega_{t}$. The lefthand side of (17) measures the utility cost of searching for a new supplier; this fixed cost does not depend on the size of the purchase. Hence, (17) implies that as the size of its purchase increases, the household's incentive to search becomes stronger.

Next, consider (6)-(8) from the perspective of the representative firm. If the firm charges price $q_{t}$ while all other firms charge price $p_{t}$, it retains a fraction $1-F\left[\left(q_{t} / p_{t}\right) \theta_{t}^{0}\right]$ of its initial customers. Thus, as the firm raises its price infinitesimally above $p_{t}$, it loses a fraction $\theta_{t}^{o} f\left(\theta_{t}^{0}\right) / p_{t}$ of its customers. Differentiating this expression with respect to $\theta_{t}^{0}$ yields

$$
\left[f\left(\theta_{t}^{0}\right)+\theta_{t}^{0} f^{\prime}\left(\theta_{t}^{0}\right)\right] / p_{t}
$$


Note from (15) that $\theta_{t}^{0}$ is increasing in $\omega_{t}$. Since (15) also implies that $\theta_{t}^{0} \leq 1$, the assumption $f^{\prime}(\theta) \geq 0$ for all $\theta \leq 1$ guarantees that the expression in (18) is positive.

Thus, when $f^{\prime}(\theta) \geq 0$ for all $\theta \leq 1$ holds, (18) implies that the strengthened incentive for any individual household to search translates into an increase in the number of additional households that actually search when the firm raises its price above $p_{t}$. In this case, the increase in $\omega_{t}$ that increases both aggregate output and the size of each household's purchase makes the demand curve facing the representative firm more elastic, inducing the firm to lower its markup. Hence, when output rises, the markup falls.

The numerical results presented in Table 1 also show that a purely transitory technology shock yields a larger drop in the markup, and hence a larger increase in output, than a permanent technology shock. In the case of a transitory shock, the representative firm knows that it will be able to charge a higher markup in the future, when output will be lower. Higher markups in the future provide the firm with a stronger incentive to cut its price today in an effort to expand its future customer base. Hence, in equilibrium, the markup falls by more than when the shock is permanent.

\section{Conclusion}

In conclusion, it must be emphasized that the model of customer flow dynamics developed here, while extending those of Phelps and Winter (1970) and Bils (1989) remains highly stylized along some dimensions. In particular, it describes preferences and technologies with simple functional forms, chosen to keep the analysis as tractable as possible. Thus, it remains to establish the extent to which the results displayed in Table 1 carry over to more general settings. Still, (17) and (18) highlight the key assumptions that will have to be satisfied, even with different specifications for preferences and technologies.

First, (17) highlights the distinction between the benefits of search, which increase with the size of the household's purchase, and the costs of search, which remain fixed. Obviously, the fixed cost of search is essential for obtaining a countercyclical markup, for if search costs increase when output goes up, households may search less during good times, reversing the effects found here. But there is an additional condition that must also be satisfied: the household's elasticity of demand for consumption must exceed one in absolute value. Only when this condition holds will the real value of the household's purchase increase when the real price of consumption falls, so that the household's incentive to search becomes stronger after a positive technology shock. As shown by (4) and (5), the utility function used here 
satisfies this elasticity condition. Many alternative specifications for utility will work as well, but others will not.

Second, (18) highlights the fact that assumptions on the density function $f$ for the idiosyncratic shocks $\theta$ must be made to guarantee that when each household has a stronger incentive to search, the demand curve facing the representative firm will become more elastic. Ball and Romer (1989) must make similar assumptions in a model where these idiosyncratic shocks help amplify the effects of monetary shocks on output. Thus, it seems likely that these assumptions will be required, even with more general specifications for preferences and technologies.

All these assumptions may prove somewhat restrictive. Yet when they are satisfied, customer flow dynamics become a powerful mechanism for amplifying the effects of technology shocks on output. The numerical results obtained here, for example, show that the output effects of a transitory technology shock can be more than nine times larger in an economy with customer flow dynamics than they would be in a purely competitive setting. Introducing these customer flow dynamics into more general and more detailed versions of the real business cycle model, therefore, appears to be a promising avenue for future research.

Received: September 1996

Final version: September 1997

\section{References}

Ball, Laurence, and David Romer. "Real Rigidities and the Non-Neutrality of Money." Review of Economic Studies 57 (April 1990): 183-203.

Bils, Mark. "The Cyclical Behavior of Marginal Cost and Price." American Economic Review 77 (December 1987): 838-55.

__. "Pricing in a Customer Market." Quarterly Journal of Economics 104 (November 1989): 699-718.

Gottfries, Nils. "Price Dynamics of Exporting and Import-Competing Firms." Scandinavian Journal of Economics 88 (1986): 417-36.

Klemperer, Paul. "Markets with Consumer Switching Costs." Quarterly Journal of Economics 102 (May 1987): 375-94.

Kydland, Finn E., and Edward C. Prescott. "Time to Build and Aggregate Fluctuations." Econometrica 50 (November 1982): 1345-70.

Long, John B., Jr., and Charles I. Plosser. "Real Business Cycles." Journal of Political Economy 91 (February 1983): 39-69.

Lucas, Robert E, Jr. Models of Business Cycles. Oxford: Basil Blackwell, 1987. 
Mankiw, N. Gregory. "Real Business Cycles: A New Keynesian Perspective." Journal of Economic Perspectives 3 (Summer 1989): 79-90.

McCallum, Bennett T. "Real Business Cycle Models." In Modern Business Cycle Theory, edited by Robert J. Barro, 16-50. Cambridge: Harvard University Press, 1989.

Morrison, Catherine J. "Productive and Financial Performance in U.S. Manufacturing Industries: An Integrated Structural Approach." Southern Economic Journal 60 (October 1993): 376-92.

Phelps, Edmund S., and Sidney G. Winter. "Optimal Price Policy under Atomistic Competition." In Microeconomic Foundations of Employment and Inflation Theory, edited by Edmund S. Phelps, 309-37. New York: W.W. Norton and Company, 1970.

Rotemberg, Julio J., and Michael Woodford. "Markups and the Business Cycle." In NBER Macroeconomics Annual 1991, edited by Olivier Jean Blanchard and Stanley Fisher, 63-129. Cambridge: MIT Press, 1991.

Summers, Lawrence $\mathbf{H}$. "Some Skeptical Observations on Real Business Cycle Theory." Federal Reserve Bank of Minneapolis Quarterly Review 10 (Fall 1986): 23-27.

Wamer, Elizabeth J., and Robert B. Barsky. "The Timing and Magnitude of Retail Store Markdowns: Evidence from Weekends and Holidays." Quarterly Journal of Economics 110 (May 1995): 321-52.

\section{Appendix}

\section{Mathematical Notation}

$i=$ index of firms.

$j=$ index of households.

$t=$ index of time periods.

$x_{i t}=$ firm $i$ s market share at the beginning of period $t$.

$\beta=$ household $j$ 's discount factor

$\theta_{j t}=$ household $j$ 's preference shock during period $t$.

$c_{j t}=$ household $j$ 's consumption during period $t$.

$n_{j t}=$ household $j$ 's labor supply during period $t$.

$\kappa=$ fixed search cost.

$s_{j t}=$ equals one if household $j$ searches during period $t$; equals zero otherwise.

$\theta_{l}, \theta_{h}=$ lower and upper bounds on $\theta_{j t}$.

$F, f=$ distribution and density functions for $\theta_{j t}$.

$w_{t}=$ wage during period $t$. 
$l_{i t}=$ labor hired by firm $i$ during period $t$.

$y_{i t}=$ output of firm $i$ during period $t$.

$z_{t}=$ technology shock during period $t$.

$\pi_{i t}=$ firm $i$ 's profits during period $t$.

$p_{i t}=$ firm $i$ 's price during period $t$.

$p_{t}=$ firms' common equilibrium price during period $t$.

$p^{t}=$ sequence of common prices from period $t$ forward.

$q_{t}=$ representative firm's price during period $t$.

$q^{t}=$ sequence of representative firm's prices from period $t$ forward.

$u=$ representative household's value function.

$c^{0}, n^{0}=$ representative household's consumption and labor supply if it does not search during period $t$.

$c^{1}, n^{1}=$ representative household's consumption and labor supply if it searches during period $t$.

$s=$ equals one if representative household searches during period $t$; equals zero otherwise.

$\pi_{t}=$ representative household's share of profits during period $t$.

$\theta_{t}^{0}=$ household $j$ searches during period $t$ if $\theta_{j t}<\theta_{t}^{0}$.

$h=$ function describing the demand curve facing the representative firm.

$\delta=$ function describing the evolution of the representative firm's market share.

$v=$ representative firm's value function.

$\omega_{t}=$ relative price $w_{t} / p_{t}$ during period $t$.

$\varepsilon=$ households' elasticity of demand for consumption.

$\bar{\theta}=$ mean value of $\theta_{j t}$.

$\sigma=$ standard deviation of $\theta_{j t}$.

$y_{t}=$ aggregate output during period $t$. 